\title{
Analysis of the implementation of patient safety management at the PKU Muhammadiyah Pekajangan Islamic Hospital
}

\author{
Irnawati $^{1}$, Benny Arief Sulistyanto ${ }^{2}$ \\ ${ }^{1} \mathrm{PhD}$ in Nursing Student, Lincoln University College, Malaysia \\ ${ }^{2}$ Department of Nursing, University of Muhammadiyah Pekajangan Pekalongan, Indonesia
}

\begin{tabular}{l} 
ARTICLE INFO \\
\hline Article history: \\
Received: August 9, 2020 \\
Revised: August 20, 2020 \\
Accepted: August 30, 2020 \\
\hline
\end{tabular}

\section{Keywords:}

Patient safety, evaluation, implementation, standard, analysis

\begin{abstract}
The Hospital applies patient safety management through seven steps toward hospital patient safety. Muhammadiyah Pekajangan Islamic Hospital already has special management that handles patient safety. The patient safety management has gone through the planning stage to evaluation. In its development, until now, there has not been an analysis of the application of patient safety management. Analysis of the application of patient safety management is important to determine whether the application of patient safety management is already running according to the established Ministry of Health standards. This study aims to analyze the application of patient safety management at the PKU Muhammadiyah Pekajangan Islamic Hospital. This study was used as a qualitative research design. The subjects in this study who conducted in-depth interviews were the PKU Muhammadiyah Pekajangan Islamic Hospital patient safety team, which consists of the head of the KPRS, who had the authority to carried outpatient safety activities, members of nursing, and members of medical support. The results showed that the application of patient safety management is performing admirably. Includes seven-step implementation of patient safety management has been actualized. The process application of patient safety management shows that the indicators were in line with the standards. It is recommended for policymakers at the PKU Muhammadiyah Pekajangan Islamic Hospital to increase efforts to implement patient safety by facilitating training for the patient safety team regarding patient safety.
\end{abstract}

This work is licensed under a Creative Commons Attribution 4.0 International License.

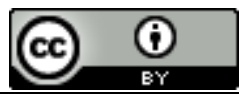

\author{
Corresponding Author: \\ Irnawati, \\ $\mathrm{PhD}$ in Nursing Student, \\ Lincoln College University, Malaysia \\ 6/12 SS Road, Petaling Jaya, Selangor Darul Ehsan 47301, Malaysia. \\ Email: sakinah.jogja@ymail.com
}

\section{INTRODUCTION}

In this era of globalization, the development of science and technology is very rapid, including medical science and technology. New medical equipment is found as well as new drugs. The situation has an impact on the health service, where in the past, health services were effortless, often less effective, but safer. At this time, the health service is very complex and more effective. However, if the service giver is less careful, it can potentially be a service error. Data in the United States of 1 in 200 people face a risk of hospital service errors, compared with a 1 per 2,000,000 risks of hospital service errors. In Indonesia, the most common cases are drug offenses that are not uncommon to be lawsuits and end up in court. Therefore, hospital patient safety is essential and is an improvement from the quality program that has been implemented conservatively. Thus, the Hospital is required to continue to develop itself and improve the quality of its services, especially in the Hospital's patient safety program [1].

Various developed countries have even shifted the "quality" paradigm towards a new "quality-safety" paradigm. Currently, efforts to improve the quality of services and improve patient safety efforts in hospitals 
are already a universal movement. This means not only the quality of service that must be improved but, more importantly, to maintain patient safety consistently and continuously. The purpose of patient safety in the Hospital is to prevent injuries caused by mistakes resulting from carrying out an action or not taking the action that should be taken. Based on this, the Association of Hospitals throughout Indonesia conducts patient safety movements in Indonesia, socializes among the hospital community, develops an action program in the form of "Seven Steps Towards Hospital Patient Safety," which includes raising awareness of the value of patient safety, leading and supporting staff, integrating risk management activities, engage and communicate with patients, learn and share experiences about patient safety, prevent injury through the implementation of safety systems[1].

Patient safety is a challenge in the field of health care, especially in hospital service settings. In recent years, patient safety has been of particular concern in the context of hospital health care. The application of patient safety is one of the mandates of the Hospital 2009 Law. Hospital accreditation in Indonesia has included the application of patient safety across the lines of both system, management, and human resources as an important assessment in deter-mining quality standards in hospitals[2].

Patient safety has been a global issue since the early 2000s, with the "To err is human, building a safer system" campaign[3]. The basic principle is that providing health care is indeed the work of a system that has the potential to experience errors. That awareness encourages the preparation of a safer system so that potential errors can be minimized. In Indonesia, patient safety campaigns began to advance in 2006 and began to become a real action with the Jakarta declaration 2007[2]. Aspects of patient safety have started to become indicators of hospital service performance in 2001 but were formally included in the Hospital Minimum Service Standard in 2008 (Decree of the Minister of Health 129/2008 on Hospital Minimum Service Standards). Aspects of patient safety also began to be included in the Hospital Accreditation Standard version 2007 from the original 16 services (version 2002), to 16 patients added patient safety. The more specific implementation of patient safety was formulated in 2011 (Regulation of the Minister of Health 1691/2011 on patient safety. This is also influenced by international hospital accreditation standards that promote patient safety as a basic concept. The Hospital Accreditation Commission has adopted patient safety issues in Indonesia since the issuance of the 2012 KARS Accreditation Standard. Since then, the implementation of patient safety has been one of the main issues[2].

The IOM/Institute of Medicine report, the United States of America in 2000, to err is human, building a safer health system" followed by WHO data (World Alliance for Patient Safety, Forward Programme, 2004) from various countries stating that in the service of inpatients in hospitals there are approximately 3-16\% Adverse Event, so the Hospital Association of Indonesia takes the initiative of inviting all hospital stakeholders to pay attention to hospital patient safety. There is now a growing demand for patients to the quality of services that do not often end up being lawsuits and damaging the Hospital's image. So hospitals are expected to routinely record and report incidents and conduct root analysis of the problem so that the incidents do not repeat itself. In line with the establishment of the Hospital, the Patient Safety Committee is crucial in helping hospitals to analyze the root of the problem and spread the problem-solving results to other hospitals so that the same incident does not happen in other hospitals[1].

Currently, the increasing demands of patients on the quality of services often end up being lawsuits and damage to the image of the Hospital. So hospitals are expected to routinely record and report incidents and conduct root analysis of the problem so that the incidents do not repeat itself. In line with the establishment of the Hospital, Patient Safety Committee is critical in helping hospitals to analyze the root of the problem and spread the problem-solving results to other hospitals so that the same incident does not happen in other hospitals[1].

Safety has become a global issue, as well as for hospitals. There are five critical issues related to hospital safety: patient safety, the safety of workers or health workers, the safety of buildings and equipment in hospitals that can impact patient and officer safety, environmental safety that affects environmental pollution, and the safety of hospital businesses related to hospital survival. These five aspects of safety are fundamental to be implemented in every Hospital. However, it must be acknowledged that hospital accommodation activities can run if there are patients. Therefore patient safety is the top priority to be implemented, and it is related to the quality and image of the hospital[1].

Admittedly, the health service is essential to save patients according to what Hippocrates said about 2400 years ago that is First, not harm. But with the development of health care science and technology, especially in hospitals, it becomes more complex and potentially the adverse event if not done carefully. In the Hospital, there are hundreds of medicines, hundreds of tests and procedures, many tools with technology, various types of professional and non-professional personnel who are ready to provide continuous 24-hour patient care. The diversity and routine of the service, if not appropriately managed, can occur adverse events[1].

Proceeding homepage: https://conferenceproceedings.ump.ac.id/index.php/pshms/issue/view/1 
In 2000 the Institute of Medicine in the United States published a report that shocked many people: "to err is human, building a safer system." The report cited research at hospitals in Utah and Colorado, and New York. In Utah and Colorado, 2.9\% of them died. Meanwhile, in New York, the event was 3.7\%, with a mortality rate of $13.6 \%$. The death rate from adverse events in inpatients across America is 33.6 million per year ranging from 44,000 - 98,000 per year. The WHO publication in 2004, collecting hospital research figures in various countries: America, The United Kingdom, Denmark, and Australia, found adverse events with a range of $3.2-16.6 \%$ [1].

In Indonesia, data on adverse events, let alone Near-miss is still rare. Still, on the other hand, there is an increase in allegations of malpractice, which is not necessarily following the final evidence. In order to improve patient safety in hospitals, the Indonesian Hospital Association has taken the initiative of establishing the Hospital Patient Safety Committee. The committee has been actively implementing preparatory measures for the implementation of hospital patient safety by developing laboratory hospital patient safety programs. Patient safety is already a demand for the public, so it is necessary to implement hospital patient safety programs[1].

According to Avedis Donabedian, to measure quality service can be reviewed through the structure, process, and results of the service provided. Structural components include organizational structure, material resources, and human resources in institutions. The organizational structure includes medical staff, committees, and patient safety teams. The process component includes all service activities performed by hospital staff and received by patients. This illustrates the effect of services provided during treatment, in the form of healing, satisfaction, increased knowledge, and avoiding adverse events[3].

Hospitals in implementing patient safety management passed seven steps toward hospital patient safety. Based on preliminary studies, PKU Muhammadiyah Pekajangan Islamic hospital already has special management that handles patient safety. Patient safety management has passed the planning stage until the evaluation. The analysis is essential to determine whether the implementation of patient safety management has been running under the department of health standards that have been established. Researchers will look at the gap between the standards of implementation of safety management from the Health Office and the reality that occurs in the PKU Muhammadiyah Pekajangan Islamic hospital. Analysis of the implementation of patient safety management to the quality of hospital services is expected to identify the implementation of patient safety management at PKU Muhammadiyah Pekajangan Islamic Hospital.

\section{RESEARCH METHOD}

This type of research was qualitative research with a case study design. The population of subjects in this study to be taken with in-depth interviews was the Patient Safety Team of PKU Muhammadiyah Pekajangan Islamic Hospital, which consists of the Head of the Hospital Patient Safety Committee, who has authority in the implementation of patient safety activities and nursing members, and medical support members. This research was conducted in August 2018 at PKU Muhammadiyah Pekajangan Islamic Hospital. Analysis of the implementation of patient safety management is to assess the implementation of patient safety management system that has been done to date compared to hospital patient safety standards issued by the Joint Commission on Accreditation of Health Organizations, Illinois, USA, the year 2002. The analysis in the study was to assess the implementation of seven safety patient management measures at PKU Muhammadiyah Pekajangan Islamic Hospital Patient Safety Hospital conducted by the Hospital or not by interview to the Hospital Patient Safety Team.

The implementation of seven measures of patient safety management is that the Hospital implements seven steps towards patient safety hospital which includes 1) build awareness of the value of patient safety; 2) lead and support your staff; 3) integrate risk management activities; 4) develop a reporting system; 5) engage and communicate with patients; 6) learn and share experiences about patient safety, and 7) prevent injury through the implementation of the patient safety system. The patient safety program was the implementation of the development of patient safety programs based on patient safety standards and patient safety targets in hospitals that include elements of standardized structures and processes, with the provision of substantial facilities and resources and the active participation of human resources will result in good outcomes and supported by a good leadership role in creating a patient safety culture will greatly determine the success of the program[1]. Primary data was obtained from in-depth interview results with research respondents and observation sheets of patient safety programs that refer to patient safety standards and patient safety targets in hospitals. Qualitative data was presented in the form of narratives further described, then the results of analysis and interpretation are continued by comparing the results of previous studies or with the theories in the literature. 


\section{RESULTS AND DISCUSSIONS}

In the management of patient safety at PKU Muhammadiyah Pekajangan Islamic Hospital, efforts to raise awareness of the value of patient safety are carried out by instilling the understanding that in patients, the incidents that always occur at the root of the problem do not blame the individual. Here's the respondent's statement 1,2,3: we instill that in each incident, always searched the root of the problem with the Root Cause Analysis method we try not to do punishment but to provide direction and coaching to the individual[4]. Building awareness of the value of patient safety can also be done by fostering a culture of daring to report every incident that occurs. Here's the question of respondent 1: we've grown a culture to report, and we've planned together that in the event of an incident to report immediately.

The second step is how to build commitment and focus on patient safety; the step is seen from the responsibility of the board of directors in the commitment of management. The board of directors' knowledge of patient safety, the willingness of the board of directors to launch patient safety movements and support for patient safety. Here is the statement of respondent 1: the director is responsible for management commitment, and very understanding about patient safety, the director who plans if the accreditation that takes precedence is patient safety.

Efforts to build a risk management system and process and to identify and assess potential problems at PKU Muhammadiyah Pekajangan Islamic Hospital exist by providing identities containing at least two things name and medical records, but in the implementation of it is added address and date of birth. The placement of the drug Look Alike Sound Alike (LASA). Here are the statements of respondents 2 and 3: The patient's wristband must have at least two identities, namely the name and medical record number but in the implementation of the written address and place of birth of the patient, and the placement of the drug LASA is not combined.

In the seven patient safety measures, the fourth step is how to engage and communicate with the patient all actions related to the patient's fixed procedure that hints at the patient's safety as an example, when performing an injection action, firstly, it necessary to recognize the drug to be injected and verify the patient starting from the name, status and type of complaint following the respondent's statement 2: all procedures must be hinted at patient safety e.g. doing injection then must recognize the drug, identify the patient, every medical implementation must verify the patient and any medical implementation must verify to the patient starting from his name his or her status type of complaint.

The root of the problem is done with Root Cause Analysis, through what, why, who, when, where, and looking for the root of the problem find a way out with the system change so that the event does not repeat itself[5]. Following the statement of respondent 1: Doing Root Cause Analysis through what, why, who, when, where, we are looking for a root problem, then searching for a way out with system changes so that the incident is not repeated. Injury prevention through the implementation of patient safety systems using existing information through patient identification, where there are standards of operational procedures for preventing patients from falling. Patients are assessed as having a moderate and high risk of mild falls provided that highrisk patients should be placed in one room with color codes, and bed identification bracelets must be out of safety. Here's the respondent's statement 1.2: there are Standard Operational Procedures prevention and provisions to minimize patients falling, such as prepared equipment Standard Operating Procedure that every patient in the assessment risk fall patient falls into the category of medium or high light risk with yellow color code and identity bracelet so that people can be aware of the patient's risk of falling, a bed there must be safety.

Based on interviews with respondents 1, 2, and 3 obtained that at PKU Muhammadiyah Pekajangan Islamic Hospital in every incident that occurs is always sought the root of the problem and does not blame the individual, trying not to do punishment but giving direction in coaching to the individual. Root-cause analysis, an essential part of risk management, is conducted after an adverse event[6]. Root-cause analysis is a process for identifying the causal risk factors that underlie variation in performance, which allows for the development of effective strategies to decrease the likelihood of similar adverse events occurring in the future[7]. According to 1,2,3 respondents that the Hospital's Patient Safety Team is making an effort to foster a culture of daring to report incidents that occur. This is reinforced by the Ministry of Department of Health Republic of Indonesia [1] statement stating that patient safety programs can run well if leaders have a clear vision, mission, and policies regarding patient safety.

The values and beliefs that must be built include reporting and discussing each adverse event without being blaming, working on a team, engaging patients in decision making, looking at a problem in the framework of the system, daring to disclose the mistakes that occur. This will give officers comfort when reporting incidents because the understanding that in every incident that occurs, always sought the root of the problem is not merely blaming the individual.

Reporting is fundamental to detecting subject safety issues. Each clinical trial protocol should clearly state the methods by which adverse events will be monitored and reported. Provisions to ensure proper care for those experiencing unfavorable and unintended signs or symptoms associated with their participation in a 
clinical trial are a necessary component as well. The protocol should also describe how information relating to adverse events is to be handled and analyzed by the investigator[8].

\section{CONCLUSION}

Efforts made by PKU Muhammadiyah Pekajangan Islamic Hospital in an effort to build awareness of the value of patient safety is to find the root of the problem in each incident and try not to blame individuals, foster a culture of daring to report every incident, conduct patient safety assessment when patients enter, discussions in the team regarding patient safety are conducted accidentally. It is recommended for policymakers at the PKU Muhammadiyah Pekajangan Islamic Hospital to increase efforts to implement patient safety by facilitating training for the patient safety team regarding patient safety.

\section{Acknowledgments}

The author would like to thank the University of Muhammadiyah Pekajangan Pekalongan for their financial support in this project. Appreciation also extended to PKU Muhammadiyah Pekajangan Islamic Hospital for provided research sites that supported the research.

\section{REFERENCES}

[1] Department of Health Republic of Indonesia, "Panduan Nasional Keselamatan Pasien Rumah Sakit (Patient Safety)," 2006.

[2] Ministry of Research and Technology, "Modul Pelatihan untuk Pelatih Keselamatan Pasien," 2015.

[3] R. Karl and M. C. Karl, "Adverse events: root causes and latent factors," Journal Surgical Clinics, vol. 92, no. 1, pp. 89-100, 2012.

[4] J. H. Rex, J. E. Turnbull, S. J. Allen, K. V. Voorde, and K. Luther, "Systematic root cause analysis of adverse drug events in a tertiary referral hospital," Journal The Joint Commission journal on quality improvement, vol. 26, no. 10, pp. 563-575, 2000.

[5] A. Lee, P. D. Mills, J. Neily, and R. Hemphill, "Root cause analysis of serious adverse events among older patients in the Veterans Health Administration," The Joint Commission Journal on Quality Patient Safety, vol. 40, no. 6, pp. 253-262, 2014.

[6] B. R. Cassin and P. R. Barach, "Making sense of root cause analysis investigations of surgery-related adverse events," Journal Surgical Clinics, vol. 92, no. 1, pp. 101-115, 2012.

[7] D. Nicolini, J. Waring, and J. Mengis, "Policy and practice in the use of root cause analysis to investigate clinical adverse events: mind the gap," Journal Social Science Medicine, vol. 73, no. 2, pp. 217-225, 2011.

[8] T. R. McCarty, K. Hathorn, D. W. Creighton, and C. C. Thompson, "Sedation under Monitored Anesthesia Care to General Endotracheal Comparative Systematic Reveiw and Metaanalysis," Journal Gastrointestinal Endoscopy, vol. 91, no. 6, p. AB344, 2020. 